\title{
Glomeruloid microvascular proliferation is associated with lack of response to chemotherapy in breast cancer
}

\author{
LA Akslen*,', O Straume', S Geisler ${ }^{2}$, T Sørlie ${ }^{3}$, J-T Chi ${ }^{4}$, T Aas $^{5}$, A-L Børresen-Dale ${ }^{3}$ and PE Lønning ${ }^{6}$ \\ 'The Gade Institute, Section for Pathology, University of Bergen, Haukeland University Hospital, Bergen N-5021, Norway; ${ }^{2}$ Department of Oncology, \\ Haukeland University Hospital, Bergen, Nonway; ${ }^{3}$ Department of Genetics, University of Oslo, Oslo, Nonway; ${ }^{4}$ The Institute of Genome Sciences and \\ Policy, Department of Molecular Genetics and Microbiology, Duke University School of Medicine, Durham, NC, USA; ${ }^{5}$ Department of Surgery, Haukeland \\ University Hospital, Bergen, Nonway; ${ }^{6}$ Institute of Medicine, Section of Oncology, University of Bergen, and Department of Oncology, Haukeland University \\ Hospital, Bergen, Norway
}

BACKGROUND: Glomeruloid microvascular proliferation (GMP), a novel histology-based angiogenesis marker, has been associated with decreased survival in several human cancers.

METHODS: In this study, we evaluated the ability of GMP to predict clinical response to neoadjuvant chemotherapy in a series of locally advanced breast cancers $(n=1 \mid 2)$.

RESULTS: Presence of GMP (21\% of the cases) was significantly associated with high-grade tumours and TP53 mutations in addition to the basal-like and HER2 subtypes of breast cancer as defined by gene expression data. GMP was correlated to a gene expression signature for tumour hypoxia response. The GMP pattern was also significantly associated with lack of treatment response and progressive disease $(P=0.004)$.

INTERPRETATION: The findings suggest that GMP might be able to predict the lack of response to neoadjuvant chemotherapy in locally advanced breast cancer. Whether GMP may be an independent predictor compared with other factors including TP53 mutation status and tumour grade needs confirmation in larger studies.

British Journal of Cancer (201 I) 1 05, 9- 12. doi:10.1038/bjc.201 I.203 www.bjcancer.com

Published online 14 June 2011

(c) 201 I Cancer Research UK

Keywords: breast cancer; neoadjuvant chemotherapy; angiogenesis; predictive factor

Angiogenesis is important for the growth and spread of malignant tumours (Carmeliet, 2003). Although vascular density has been correlated to survival in different malignancies (Weidner et al, 1991, 1992; Hlatky et al, 2002; Uzzan et al, 2004), angiogenesis markers have not been associated with response to chemotherapy or anti-angiogenesis treatment (Paulsen et al, 1997; Tynninen et al, 2002; Jubb et al, 2006). Glomeruloid microvascular proliferations (GMP), a novel angiogenesis marker, are focal aggregates of small vessels resembling a renal glomerulus (Pettersson et al, 2000; Sundberg et al, 2001). In mice, GMP has been induced by local injection of an adenovirus vector directing VEGF-A expression (Sundberg et al, 2001). A human parallel appears to be the POEMS syndrome, where increased VEGF-A is associated with glomeruloid haemangiomas (Tsai et al, 2001). In humans, GMP is a defining histological feature of glioblastoma multiforme (Wesseling et al, 1993; Schiffer et al, 1999) and a prognostic factor in several other tumours (Straume et al, 2002; Tanaka et al, 2003; Foulkes et al, 2004). In this study of locally advanced breast cancer, GMP showed a significant association with lack of treatment response and progressive disease following chemotherapy.

*Correspondence: Dr LA Akslen; E-mail: lars.akslen@gades.uib.no Received 28 January 201 I; revised 10 May 20 II; accepted 12 May 20 II; published online I4 June 201 |

\section{PATIENTS AND METHODS}

\section{Patients}

The patients included in this study were all treated in two prospective single-arm studies for locally advanced breast cancer (T3/T4 and/or N2 tumours) at the Department of Oncology, Haukeland University Hospital (Bergen, Norway). Briefly, in the first study (carried out during 1991-1996), each patient $(n=94$; median age 64 yrs) received doxorubicin monotherapy administered at a dose of $14 \mathrm{mg} \mathrm{m}^{-2}$ on a weekly basis (Aas et al, 1996; Geisler et al, 2001). In the second study (carried out during 1993-2000), 35 patients (median age 67 years) received 5-FU $1000 \mathrm{mg} \mathrm{m}^{-2}$ on day 1 and 2 with mitomycin $6 \mathrm{mg} \mathrm{m}^{-2}$ day 2 at 3-weekly intervals (Geisler et al, 2003). Patients were recruited by the same clinical criteria, with no selection, and tissue was obtained by open surgical biopsy. Clinical responses were classified as complete response (CR), partial response (PR), progressive disease (PD), and stable disease (SD) according to the UICC criteria generally applied at the time period these clinical studies were conducted (Hayward et al, 1977). Tumour size in general was measured with use of calipers on a 4-weekly (doxorubicin protocol) or 3-weekly basis (5FU/mitomycin protocol). In case a PD was recorded (25\% increase in the product of perpendicular diameters), the patient immediately terminated this chemotherapy and was allocated for an alternative treatment option. For internal consistency, we compared tumours with PD 
with the combined group of SD/PR/CR, similar to what was conducted in our previous reports from the same materials (Geisler et al, 2001, 2003).

\section{Basic variables and immunohistochemistry}

Histological type and histological grade (Elston and Ellis, 1991) were recorded, as well as lymph node status. Staining of endothelial cells by Factor-VIII antibody A-0082 (Dako, Copenhagen, Denmark) was performed on paraffin-embedded archival material (Straume et al, 2002). Of a total of 129 cases, sufficient tissue for reliable analysis was available in 112 cases; one histological slide was examined from each case with selection of the highest tumour grade in case of heterogeneity. Positivity for GMP was recorded on the initial surgical biopsy by one observer (OS) and defined as the presence of focal glomerulus-like aggregates of closely associated and multilayered Factor-VIIIpositive endothelial cells (Pettersson et al, 2000; Sundberg et al, 2001; Straume et al, 2002). Recorded GMPs or 'glomeruloid bodies' typically consisted of 15-100 cells. Glomeruloid microvascular proliferation status was reported as absent or present (one GMP was sufficient to define the case as positive; in most cases more GMPs were observed).

\section{Mutations and gene expression}

Mutations in the TP53 gene (exons 2-11) were analysed using genomic DNA and TTGE (temporal temperature gradient gel electrophoresis) as reported (Aas et al, 1996; Geisler et al, 2001). Microarray data were available from previous studies in 78 cases (Perou et al, 2000; Sorlie et al, 2001, 2003), and analysis of a hypoxia-related expression signature was carried out (Chi et al, 2006). The hypoxia signature reflects the most differentially expressed genes in epithelial cells after hypoxia in vitro (mammary epithelial cells and renal tubular cells).

\section{Statistical analysis}

Associations between different categorical variables were evaluated by Pearson's $\chi^{2}$-test, Fisher's exact test or McNemar's test. Statistical significance was assessed at the two-sided 5\% level. Prediction of disease progression was analysed by logistic regression. The data were analysed using the SPSS version 15.0 statistical software (SPSS Inc., Chicago, IL, USA).

\section{RESULTS}

Glomeruloid microvascular proliferation positivity was present in 24 of 112 primary tumours (21\%) (Table 1). In 56 cases with tissue available after chemotherapy, the frequency of GMP + increased from 16 to $32 \%$ (McNemar's test, $P=0.035$ ). Regarding histological features, $25 \%$ of ductal carcinomas were GMP + , compared with $0 \%$ of non-ductal tumours (Fisher's exact test, $P=0.038$ ). Glomeruloid microvascular proliferation positivity was associated with histological grade (frequency of 0,14 and $40 \%$ in grades $1-3$, respectively; $P=0.001$ ) and lymph node status in particular (pN0-1: 12\% GMP +, pN2: 38\% GMP +; $P=0.011)$ (Table 1).

Glomeruloid microvascular proliferation positivity was significantly associated with lack of response to treatment (PD). Of 17 cases with PD, GMP + was found in eight cases (47\%), compared with $16 \%$ among the rest (Pearson's $\chi^{2}$-test, $P=0.004$ ). Conversely, $35 \%$ of GMP + cases showed progressive disease, compared with $10 \%$ among GMP - cases $(P=0.004)$. Further, there was a strong association between GMP + and TP53 mutation status (TP53 mutated tumours, 38\% GMP + ; wtTP53 tumours, $11 \% \mathrm{GMP}+$; $\left.\chi^{2}=11.1, P=0.001\right)$. This association persisted when mutations in the L2/L3 domain were compared with other mutations and
Table I Associations between GMP status and important tumour characteristics, as well as treatment response

\begin{tabular}{|c|c|c|c|c|c|}
\hline \multirow[b]{2}{*}{ Variables } & \multicolumn{2}{|c|}{ GMP present } & \multicolumn{2}{|c|}{ GMP absent } & \multirow[b]{2}{*}{$P$-value ${ }^{a}$} \\
\hline & No. & $\%$ & No. & $\%$ & \\
\hline Histological type & & & & & 0.038 \\
\hline Ductal & 24 & 25 & 73 & 75 & \\
\hline Others & 0 & 0 & 15 & 100 & \\
\hline Histological grade & & & & & 0.001 \\
\hline Grade I & 0 & 0 & 17 & 100 & \\
\hline Grade 2 & 7 & 13 & 45 & 87 & \\
\hline Grade 3 & 17 & 40 & 26 & 60 & \\
\hline Lymph node status & & & & & 0.011 \\
\hline No & 5 & 15 & 28 & 85 & \\
\hline $\mathrm{NI}$ & 5 & 12 & 37 & 88 & \\
\hline N2 & 14 & 38 & 23 & 62 & \\
\hline TP53 mutations & & & & & 0.001 \\
\hline Absent & 8 & 11 & 62 & 89 & \\
\hline Present & 16 & 38 & 26 & 62 & \\
\hline Hypoxia signature & & & & & 0.041 \\
\hline Negative & 10 & 20 & 40 & 80 & \\
\hline Positive & 12 & 41 & 17 & 59 & \\
\hline Molecular subtype $\mathrm{b}^{\mathrm{b}}$ & & & & & $0.040^{c}$ \\
\hline Luminal A & 5 & 15 & 28 & 85 & \\
\hline Luminal B & 3 & 23 & 10 & 77 & \\
\hline HER2 & 8 & 44 & 10 & 56 & \\
\hline Basal-like & 4 & 33 & 8 & 67 & \\
\hline Normal-like & 1 & 50 & 1 & 50 & \\
\hline Clinical response $^{d}$ & & & & & 0.004 \\
\hline Non-PD & 15 & 16 & 79 & 84 & \\
\hline PD & 8 & 47 & 9 & 53 & \\
\hline
\end{tabular}

Abbreviations: $\mathrm{GMP}=$ glomeruloid microvascular proliferation; $\mathrm{PD}=$ progressive disease. ${ }^{a} P$-value by Pearson's $\chi^{2}$-test or Fisher's exact test; 'Molecular subtype is based on microarray data (from Perou et al, 2000; Sorlie et al, 200 I, 2003); 'Basal-like and HER2 tumours combined were compared with the rest; ${ }^{d}$ Non-PD is a combination of complete response, partial response, and stable disease.

wild-type tumours combined $\left(\chi^{2}=8.8, P=0.003\right)$. However, GMP + was also observed in TP53 wild-type cases $(n=69)$ and tended to show an association with progressive disease within this subgroup: two GMP positive of six in the PD group $(33 \%)$ vs five GMP positive of $63(8 \%)$ among the others; Pearson's $\chi^{2}$-test: $P=0.049$; Fisher's exact test: $P=0.11$. Logistic regression analysis revealed TP53 mutations (wild type and non-L2/L3 vs L2/L3 mutations) to predict disease progression independently $(P=0.005)$ (Aas et al, 1996; Geisler et al, 2003), whereas GMP status showed an independent association with disease progression of borderline significance $(P=0.07)$. When cases with either TP53 mutation (L2/L3 type) or GMP + were combined, there was a highly significant association with disease progression (PD) $(P=0.001)$.

When looking at gene expression patterns in relation to GMP status (78 cases available from the doxorubicin-treated series), statistical analysis of microarrays (SAM) between GMP-positive and -negative tumours revealed that 76 genes were significantly downregulated in GMP-positive cases (none were significantly upregulated; false discovery rate $20 \%$ ), five of these genes more than twofold: NAT1 (N-acetyltransferase 1), ESR1 (estrogen receptor 1), TFF3 (trefoil factor 3), PLAT (plasminogen activator, tissue), and HIST2H2BE (histone cluster 2, H2BE). Of these, two genes (TFF3, PLAT) have been involved in angiogenesis regulation.

Glomeruloid microvascular proliferation was also associated with a hypoxia-related gene expression signature, which was 
present in 37\% of all tumours and more frequent in GMP-positive cases $(55 \%)$ when compared with GMP-negative tumours $(30 \%)$ $(P=0.041)$. Positivity for the hypoxia signature was significantly associated with basal-like tumours ( $83 \%$ compared with $29 \%$ among the others; $P=0.0003$; the signature was positive in only $3 \%$ of luminal A cases).

The GMP frequency was increased among the aggressive basallike and HER2 subgroups of breast cancer based on gene expression data on these cases (GMP frequency: basal-like 33\%, HER2 44\%, luminal-A 15\%, luminal-B 23\%; $P=0.040$ ) (Perou et al, 2000; Sorlie et al, 2001).

\section{DISCUSSION}

Our findings indicate an association between GMP and lack of clinical response to neoadjuvant chemotherapy in a series of locally advanced breast cancers. In previous studies, no relationship between standard microvessel density and treatment response was observed (Paulsen et al, 1997; Tynninen et al, 2002; Jubb et al, 2006). Here, GMP was significantly correlated to the presence of TP53 mutations, which might be pathogenetically involved in this angiogenic phenotype (Dameron et al, 1994; Foulkes et al, 2004). Previous studies have implicated TP53 in angiogenesis regulation through mechanisms involving TSP-1, bFGF-binding protein, HIF-1 $\alpha$ and VEGF (Dameron et al, 1994; Ravi et al, 2000; Zhang et al, 2000; Sherif et al, 2001; Pore et al, 2004). However, GMP was also observed in mutation-negative tumours, indicating that TP53 could represent one of several possible pathways. As the hypoxia signature was more frequent in GMP-positive tumours, GMP formation might be stimulated by hypoxia-related pathways, like HIF- $1 \alpha$ activation and increased VEGF expression. Taken together, our findings suggest that TP53 mutations and tumour hypoxia may both be related to the pathogenesis of this angiogenic phenotype in human breast cancer.

Interestingly, in a subset of the cases where tissue was available for study after treatment, the frequency of GMP was significantly increased (from $16 \%$ among the initial biopsies to $32 \%$ posttreatment in paired samples). It is not clear, however, whether this reflects a sampling effect or a selection of more aggressive and treatment resistant tumour components.

In summary, a significant association between GMP and lack of response to neoadjuvant chemotherapy in locally advanced breast cancer is indicated. Future studies are needed to assess the potential predictive value of GMP for targeted anti-angiogenesis treatment in breast cancer and other tumours.

\section{ACKNOWLEDGEMENTS}

We would like to thank GL Hallseth, B Nordanger, D Ekse, $\mathrm{H}$ Berntsen, B Leirvaag, L-M Jørgensen, and $\mathrm{P} \mathrm{Vu}$ for excellent technical assistance. The studies were supported by grants from the Norwegian Cancer Society, the Norwegian Research Council, and Helse Vest Research Fund (LAA).

\section{REFERENCES}

Aas T, Borresen AL, Geisler S, Smith-Sørensen B, Johnsen H, Varhaug JE, Akslen LA, Lønning PE (1996) Specific P53 mutations are associated with de novo resistance to doxorubicin in breast cancer patients. Nat Med 2: $811-814$

Carmeliet P (2003) Angiogenesis in health and disease. Nat Med 9: 653-660 Chi JT, Wang Z, Nuyten DS, Rodriguez EH, Schaner ME, Salim A, Wang Y, Kristensen GB, Helland A, Børresen-Dale AL, Giaccia A, Longaker MT, Hastie T, Yang GP, van de Vijver MJ, Brown PO (2006) Gene expression programs in response to hypoxia: cell type specificity and prognostic significance in human cancers. PLoS Med 3: e47

Dameron KM, Volpert OV, Tainsky MA, Bouck N (1994) Control of angiogenesis in fibroblasts by p53 regulation of thrombospondin-1. Science 265: $1582-1584$

Elston CW, Ellis IO (1991) Pathological prognostic factors in breast cancer. I. The value of histological grade in breast cancer: experience from a large study with long-term follow-up. Histopathology 19: 403-410

Foulkes WD, Brunet JS, Stefansson IM, Straume O, Chappuis PO, Bégin LR, Hamel N, Goffin JR, Wong N, Trudel M, Kapusta L, Porter P, Akslen LA (2004) The prognostic implication of the basal-like (cyclin E high/p27 low/p53+/glomeruloid-microvascular-proliferation+) phenotype of BRCA1-related breast cancer. Cancer Res 64: 830-835

Geisler S, Borresen-Dale AL, Johnsen H, Aas T, Geisler J, Akslen LA, Anker G, Lønning PE (2003) TP53 gene mutations predict the response to neoadjuvant treatment with 5-fluorouracil and mitomycin in locally advanced breast cancer. Clin Cancer Res 9: $5582-5588$

Geisler S, Lonning PE, Aas T, Johnsen H, Fluge O, Haugen DF, Lillehaug JR, Akslen LA, Børresen-Dale AL (2001) Influence of TP53 gene alterations and c-erbB-2 expression on the response to treatment with doxorubicin in locally advanced breast cancer. Cancer Res 61: 2505-2512

Hayward JL, Rubens RD, Carbone PP, Heuson J-C, Kumaoka S, Segaloff A (1977) Assessment of response to therapy in advanced breast cancer. $\mathrm{Br} J$ Cancer 35: $292-298$

Hlatky L, Hahnfeldt P, Folkman J (2002) Clinical application of antiangiogenic therapy: microvessel density, what it does and doesn't tell us. J Natl Cancer Inst 94: 883-893

Jubb AM, Hurwitz HI, Bai W, Holmgren EB, Tobin P, Guerrero AS, Kabbinavar F, Holden SN, Novotny WF, Frantz GD, Hillan KJ, Koeppen $\mathrm{H}$ (2006) Impact of vascular endothelial growth factor-A expression, thrombospondin-2 expression, and microvessel density on the treatment effect of bevacizumab in metastatic colorectal cancer. J Clin Oncol 24: $217-227$

Paulsen T, Aas T, Borresen AL, Varhaug JE, Lønning PE, Akslen LA (1997) Angiogenesis does not predict clinical response to doxorubicin monotherapy in patients with locally advanced breast cancer (letter). Int $J$ Cancer 74: $138-140$

Perou CM, Sorlie T, Eisen MB, van de Rijn M, Jeffrey SS, Rees CA, Pollack JR, Ross DT, Johnsen H, Akslen LA, Fluge O, Pergamenschikov A, Williams C, Zhu SX, Lønning PE, Børresen-Dale AL, Brown PO, Botstein D (2000) Molecular portraits of human breast tumours. Nature 406: 747-752

Pettersson A, Nagy JA, Brown LF, Sundberg C, Morgan E, Jungles S, Carter R, Krieger JE, Manseau EJ, Harvey VS, Eckelhoefer IA, Feng D, Dvorak AM, Mulligan RC, Dvorak HF (2000) Heterogeneity of the angiogenic response induced in different normal adult tissues by vascular permeability factor/vascular endothelial growth factor. Lab Invest 80: $99-115$

Pore N, Liu S, Shu HK, Li B, Haas-Kogan D, Stokoe D, Milanini-Mongiat J, Pages G, O'Rourke DM, Bernhard E, Maity A (2004) Sp1 is involved in Akt-mediated induction of VEGF expression through an HIF-1independent mechanism. Mol Biol Cell 15: 4841-4853

Ravi R, Mookerjee B, Bhujwalla ZM, Sutter CH, Artemov D, Zeng Q, Dillehay LE, Madan A, Semenza GL, Bedi A (2000) Regulation of tumor angiogenesis by p53-induced degradation of hypoxia-inducible factor 1alpha. Genes Dev 14: $34-44$

Schiffer D, Bosone I, Dutto A, Di Vito N, Chiò A (1999) The prognostic role of vessel productive changes and vessel density in oligodendroglioma. I Neurooncol 44: 99-107

Sherif ZA, Nakai S, Pirollo KF, Rait A, Chang EH (2001) Downmodulation of bFGF-binding protein expression following restoration of p53 function. Cancer Gene Ther 8: $771-782$

Sorlie T, Perou CM, Tibshirani R, Aas T, Geisler S, Johnsen H, Hastie T, Eisen MB, van de Rijn M, Jeffrey SS, Thorsen T, Quist H, Matese JC, Brown PO, Botstein D, Eystein Lønning P, Børresen-Dale AL (2001) Gene expression patterns of breast carcinomas distinguish tumor subclasses with clinical implications. Proc Natl Acad Sci USA 98: $10869-10874$

Sorlie T, Tibshirani R, Parker J, Hastie T, Marron JS, Nobel A, Deng S, Johnsen H, Pesich R, Geisler S, Demeter J, Perou CM, Lønning PE, Brown PO, Børresen-Dale AL, Botstein D (2003) Repeated observation of breast 
GMP vs lack of response to chemotherapy in breast cancer LA Akslen et al

tumor subtypes in independent gene expression data sets. Proc Natl Acad Sci USA 100: $8418-8423$

Straume O, Chappuis PO, Salvesen HB, Halvorsen OJ, Haukaas SA, Goffin JR, Bégin LR, Foulkes WD, Akslen LA (2002) Prognostic importance of glomeruloid microvascular proliferation indicates an aggressive angiogenic phenotype in human cancers. Cancer Res 62: 6808-6811

Sundberg C, Nagy JA, Brown LF, Feng D, Eckelhoefer IA, Manseau EJ, Dvorak AM, Dvorak HF (2001) Glomeruloid microvascular proliferation follows adenoviral vascular permeability factor/vascular endothelial growth factor-164 gene delivery. Am J Pathol 158: 1145-1160

Tanaka F, Oyanagi H, Takenaka K, Ishikawa S, Yanagihara K, Miyahara R, Kawano Y, Li M, Otake Y, Wada H (2003) Glomeruloid microvascular proliferation is superior to intratumoral microvessel density as a prognostic marker in non-small cell lung cancer. Cancer Res 63: $6791-6794$

Tsai CY, Lai CH, Chan HL, Kuo T (2001) Glomeruloid hemangioma a specific cutaneous marker of POEMS syndrome. Int J Dermatol 40: 403-406

Tynninen O, Sjostrom J, von Boguslawski K, Bengtsson NO, Heikkilä R, Malmström P, Ostenstad B, Wist E, Valvere V, Saksela E, Paavonen T, Blomqvist C (2002) Tumour microvessel density as predictor of chemotherapy response in breast cancer patients. $B r J$ Cancer 86: $1905-1908$

Uzzan B, Nicolas P, Cucherat M, Perret GY (2004) Microvessel density as a prognostic factor in women with breast cancer: a systematic review of the literature and meta-analysis. Cancer Res 64: 2941-2955

Weidner N, Folkman J, Pozza F, Bevilacqua P, Allred EN, Moore DH, Meli S, Gasparini G (1992) Tumor angiogenesis: a new significant and independent prognostic indicator in early-stage breast carcinoma. $J$ Nat Cancer Inst 84: $1875-1887$

Weidner N, Semple JP, Welch WR, Folkman J (1991) Tumor angiogenesis and metastasis - correlation in invasive breast carcinoma. $N$ Engl J Med 324: $1-8$

Wesseling P, Vandersteenhoven JJ, Downey BT, Ruiter DJ, Burger PC (1993) Cellular components of microvascular proliferation in human glial and metastatic brain neoplasms. A light microscopic and immunohistochemical study of formalin-fixed, routinely processed material. Acta Neuropathol 85: $508-514$

Zhang L, Yu D, Hu M, Xiong S, Lang A, Ellis LM, Pollock RE (2000) Wild-type p53 suppresses angiogenesis in human leiomyosarcoma and synovial sarcoma by transcriptional suppression of vascular endothelial growth factor expression. Cancer Res 60: 3655-3661 